\title{
Results of the adaptive selection of vegetables in conditions of climate change
}

\author{
Lymar V. ${ }^{1}$, Holodniak O. ${ }^{2}$ \\ South State Agricultural Experiment Station of Institute of Water Problems and Melioration of NAAS, \\ 71 Chornomorska Str., Hola Prystan, Kherson oblast, 75600, Ukraine \\ e-mail: ipobuaan@ gmail.com; ORCID: ${ }^{10000-0002-2259-2655, ~}{ }^{20000-0002-1513-6911 ~}$
}

Goal. To determine sources of economically valuable signs, to establish relationships between the morphological characteristics of plants and resistance to harmful environmental factors and to create varieties of vegetable and melon crops adapted to cultivation in the steppe zone of Ukraine. Methods. Laboratory, field, and statistical. Results. For tomato the relationship between the length of the period "germination - fruit ripening and flowering - ripening" $(r=0,89)$ is determined. For sweet pepper and eggplant the relationship between the length of the period of "shoots - biological ripeness" and "flowering - biological ripeness" ( $r=0.66$ and $r=0,76$ respectively) is determined. For the watermelon there is a link between the length of vegetative period and "tying — ripening" ( $r=0.57)$, heat resistance and the number of breaths on the underside of the leaf $(r=0,69)$, between the temperature of the upper and lower sides of the leaf and drought resistance, which is respectively $r=(-0,59)$ and $r=(-0,52)$. The correlation is fixed between laboratory resistance and the number of breaths on the underside of the leaf of pumpkin in the field of view of the microscope at the magnification of 40 times $(r=0.74)$, cold resistance and area of the leaf $(r=0.51)$ and length of internodes $(r=0.51)$, between productivity, length of cotyledons $(r=0.53)$ and length of the main stem $(r=0.52)$. The zucchini correlates with the heat resistance and the number of spines on the stalk $(r=0.63)$, cold resistance and number of leaves per plant $(r=0,43)$. The bush pattypan correlates with the heat and the length of the stake $(r=0.56)$. The productivity of plants of muscat pumpkins has a high correlation with the length of the main stem $(r=0.84)$ and medium with fruit weight $(r=0.56)$. Fruit weight is negatively correlated with the number of fruits per plant $r=(-0,62)$. The number of seeds per fruit correlates with the hardness of the bark of the fruit $(r=0,71)$ and fruit width $(r=0,61)$. The hardness of the bark is positively correlated with fruit width $(r=0,86)$. Conclusions. Over 20 years of successful work of selection workers of Southern agricultural station it has been created more than 60 varieties of vegetable and melon crops, which by their economic characteristics equal to world analogs, and as to resistance against harmful environmental factors they surpass them.

Key words: productivity, morphological characteristics, communications, correlation.

DOI: https://doi.org/10.31073/agrovisnyk202003-07

The rate of increase of air temperature over the last 100 years on the territory of Ukraine is twice the global indicators. The most difficult conditions for the development of crop production are observed in the southern regions - Mykolaiv and Kherson [1]. When creating high-yielding varieties that can stably realize their potential under the influence of harmful environmental factors, breeders have some difficulties negative correlations between the productivity potential and the resistance of plants to environmental stresses [2]. Therefore, the study of the patterns of relationships between the main features of the plant becomes relevant, with the aim of breeding new productive with high quality fruits of varieties of vegetable and melons, adapted to growing in the conditions of the steppe zone of Ukraine.

Analysis of recent research and publications. In modern breeding programs, the search for links between different plant characteristics is the key to obtaining the planned results. Depending on the purpose, the relationships between the structural components of the crop [3-5], the resistance to abiotic environmental factors [6], the chemical composition of the fruits [7] are investigated.

Purpose of research. Identify sources of economic value, establish relationships between plant morphological features and resistance to harmful environmental factors, and create varieties of vegetable and melon crops adapted to cultivation in the steppe zone of Ukraine.

Materials and methods of research. The studies were conducted in open soil at the drip irrigation site located in the State Enterprise "Velikiy Klin" (46. $19^{\prime} 46.1$ "N 32 $\left.35^{\prime} 51.2^{\prime \prime} \mathrm{E}\right)$ of the Southern State Agricultural Experimental Station of the Institute of Agricultural Sciences of the NAAS in 1998-2018.

Agrotechnics in the experiments conformed to DSTU 6008:2008 Tomato. Growing technology. General requirements. DSTU 5044:2008 Peppers and eggplants. Growing technology. General requirements. DSTU 5045: 2008 Watermelon, watermelon, pumpkin.

Growing technology. Substantive provisions. DSTU 6016-2008 Cucumber, squash, squash. Growing technology. General requirements. DSTU 5046: 2008 Seeds of watermelon, melon, pumpkin. Harvesting and accounting were done manually, by weight, and samples were taken for chemical analysis of the fruits. Fruit analysis was performed according to DSTU 4945:2008, DSTU 4954:2008, DSTU 4957:2008. Assessment of collection samples for abiotic stability in laboratory conditions was carried out according to 
appropriate methodological guidelines $[8,9]$. Statistical processing of the research results was carried out according to the manual "System analysis in the selection of field crops" [10].

Results. The station's scientists, taking into account critical climate changes, have developed a program for the selection of varieties of vegetable and melon crops that are resistant to the negative effects of abiotic environmental factors. As a result of the implementation of this program, methods for determining in laboratory and field conditions the relative resistance of vegetables and melons to heat, drought and cold have been developed and improved. For each culture, osmotic pressure, temperature, exposure to the effects of negative factors, which allow to distribute the studied material, by resistance groups and to purposely select the best genotypes, were determined in the laboratory. In the field, deep biometric studies of vegetables and melons and phenological observations during their growing season were conducted.

Correlation analysis of the characteristics of tomato, eggplant and sweet pepper plants revealed that these cultures have a high correlation between laboratory heat resistance and the number of breaths per leaf, which is $r=0.84$ for eggplant, $r=0.81$ and sweet pepper $-r=0.82$.

In the study of the growing season, the tomato has a high correlation between the length of the period "sprouting - ripening of the fruit" and the length of the interphase period "flowering - ripening" $(r=0.89)$. Therefore, when breeding for maturity, it is necessary to select samples with a short interphase period of "flowering - ripening". For sweet and eggplant pepper plants, a high correlation was found between the length of the "seedling - biological ripeness" period and the interfacial period "flowering biological ripeness" $(r=0.66$ and $r=0.76$ respectively). On the basis of the correlation dependences obtained, it can be concluded that in order to reduce the period "seedlings - biological maturity", it is necessary to select for a short interphase period "flowering-biological maturity". This is especially important when creating varieties of sweet peppers, the fruits of which are used in biological maturity.

The obtained correlation ligaments allowed to create tomato varieties Apologet, Anaconda, Adel, Ukrainec, sweet pepper - Zlato Skifif, Bagryanuy Vulkan, Canyon, Zvenigora, eggplant - Khersonskiy, Iceberg, Zabava.

Watermelon plants have a relationship between the length of the growing season and the "fruitbinding" phase $(r=0.57)$. In order to reduce the period of "sprouting - reaching the fruits", it is necessary to select for a short interphase period of "tying-reaching the fruits". As a result of correlation analysis, there was a significant relationship between the heat resistance of the watermelon samples and the number of breaths on the underside of the leaf $(r=0.69)$, between the temperature of the upper and lower sides of the leaf and drought resistance, which is respectively $r=(-0.59)$ and $r=(-0.52)$.

The presence of these connections allowed in the field to analyze a large amount of starting material and create such varieties of watermelon, such as Alliance, Charivnik, Mriya.

At the station, a correlation was found between laboratory heat resistance and the number of breaths on the underside of a large-fruited pumpkin leaf in the field of view of the microscope at 40 times magnification $(r=0.74)$, between the cold resistance determined in the laboratory and the leaf area $(r=$ $0.51)$ and internode length $(r=0.51)$, between productivity, cotyledon length $(r=0.53)$, and main stem length $(r=0.52)$.

As a result, new varieties of large-fruited pumpkin Altair, Universal, Siriy Ukrainskiy, Stepovyi were created.

Zucchini showed a correlation between heat resistance and the number of thorns per petiole $(r=0.63)$, between cold resistance and the number of leaves per plant $(r=0.43)$. The patison showed a correlation between heat resistance and the length of the petiole $(r=0.56)$.

These correlative relationships made it possible to create varieties of squash Haydamak. Acrobat, Ataman, Zlatogor and Cardamon.

It was found that the productivity of the muscat pumpkin plant has a high positive correlation with the length of the main stem $(r=0.84)$ and the average - with the weight of the fruit $(r=0.56)$. The weight of the fruit negatively correlates with the number of fruits on the plant $(r=(-0.62))$. More male flowers on the plant produce more pollen, which improves the pollination conditions of female flowers. Therefore, the productivity of muscat pumpkin plants correlates positively with the ratio of male flowers to female $(r=0.65)$. The number of seeds in the fruit correlates positively with the bark hardness $(r=0.71)$ and the width of the root $(r=0.61)$. Bark hardness, in turn, correlates positively with fetal width $(r=0.86)$. Due to the fact that the fruits of the Turkmen subspecies of the muscat pumpkin have significant features in the structure (form with the placement of seeds on one side only), we performed correlation analysis separately for this subspecies and all others. As a result, differences were found in both the strength and the direction of the individual relationships between the morphological characteristics of the fruit. For example, for the Turkmen subspecies, a positive relationship was found between fetal mass and length $(r=0.94)$, width $(r=0.95)$, index $(r=0.90)$, and pulp thickness $(r=0.96)$. Other subspecies of Muscat pumpkin have a negative relationship between the mass of the fruit and its width $(r=(-0.86))$ and the thickness of the pulp $(r=$ $(-0.40)$ ). The bark hardness of the fruits of the Turkmen subspecies is positively correlated with the weight of the fruit 0,48 . In the other subspecies, the opposite is $(r=(-0.68))$ and $(r=0.92)$, respectively. Correlations were also found between the signs: dry soluble content - starch content $(r=0.97)$, dry soluble content carotene content $(r=(-0.72))$. The sign "number of nodes to the first germ" in the nutmeg gourd positively correlates with the number of nodes between the female flowers $(r=0.70)$ and the length of the petiole 
$(r=0.69)$ and negatively - with the diameter of the main stem $(r=(-0.55))$. In turn, the length of the petiole is closely related to the length $(r=0.70)$ and the width of the leaf $(r=0.84)$. It was also found that the surface temperature of the leaf plate of the muscat pumpkin plants has a high negative correlation with the number of nodes before the first germ $(r=(-0.80-(-0.75))$.

Using the obtained data varieties of muscat pumpkins Yanina, Radzynka, Divo were created and regionalized for the steppe zone of Ukraine.

\section{Conclusions}

During the 20 years of successful work of the breeders of the Southern Agricultural Station, more than 60 varieties of vegetable and melon crops have been created, which in their economically valuable features are not inferior to the world analogues, and surpass them in their resistance to harmful environmental factors.

\section{References}

1. Tarariko, O. G., Sirotenko, O. V., \& Velichko, V. A. (2012). Kosmichnyi monitorynh posushlyvykh yavyshch [Space monitoring of arid phenomena]. Bulletin of Agricultural Science, 10, 12-19. [In Ukrainian].

2. Zhuchenko, A. A. (1994). Strategiya adaptivnoy intensifikatsii selskogo khozyaystva (kontseptsiya) [Strategy of adaptive intensification of agriculture (concept)]. Pushchino: ONTI, Russian Academy of Sciences. [In Russian].

3. Krasteva, L., Velcheva, N., \& Mokreva, T. (2012). Principal component analysis of a canning determinate tomato collection in the IPGR, Sadovo. Bulgaria, Agro-Knowledge, 13(1), 79-86.

4. Islam, B. M. R., Ivy, N. A., Rasul, M. G., Zakaria, M., \& Islam, B. M. R. (2010). Character association and path analysis of exotic tomato (Solanum lycopersicum L.) genotypes. Bangladesh. J.Pl. Breed. Genet, 23(1), 13-18.

5. Chernet, S., Belew, D., \& Abay, F. (2014). Genetic diversity studies for quantitative traits of tomato (Solanum lycopersicon L.) genotypes in Western Tigray. Northern Ethiopia. J. Plant Breed. Crop Sci., 6(9), 105-113.

6. Brdar-Jokanovic, M., Pavlovic, S., Girek, Z., Ugrinovic, M., \& Zdravkovic, J. (2014). Assessing Tomato Drought Tolerance Based on Selection Indices. Ratar. Vegetable, 51(1), 38-45.

7. Hernandez Suarez, M., Rodrıguez, E. M., \& Diaz Romero, C. (2008). Chemical composition of tomato (Lycopersicon esculentum) from Tenerife. Canary Islands. Food Chemistry, 106, 1046-1056.

8. Kravchenko, V. A., \& Prulipka, O. V. (2001). Metodyka i tekhnika selektsiinoi roboty z tomatom [The technique and technique of breeding with tomato]. Kyiv: Agrarian Science. [In Ukrainian].

9. Kravchenko, V. A., Holodniak, O. G., \& Voevodin, Y. I. (2010). Metodychni rekomendatsii z vyznachennia zharostiikosti zrazkiv ovochevykh kultur (ohirok, pomidor, perets, baklazhan) [Guidelines for determining the heat resistance of vegetable samples (cucumber, tomato, pepper, eggplant)]. Scientific and methodical edition. Kherson: Ilant. [In Ukrainian].

10. Litun, P. P., Kirichenko, V. V., Petrenkova, V. P., \& Kolomatska, V. P. (2009). Systemnyi analiz v selektsii polovykh kultur [System analysis in field crop breeding]. Kharkiv. [In Ukrainian]. 